\title{
Constructed nets with perturbations for equilibrium and fixed point problems
}

Yonghong Yao ${ }^{1}$, Yeol Je Cho ${ }^{2,3 *}$, Yeong-Cheng Liou ${ }^{4}$ and Ravi P Agarwal ${ }^{3,5}$

This paper is dedicated to Professor Shih-sen Chang for his 80th birthday.

"Correspondence: yjcho@gnu.ac.kr

${ }^{2}$ Department of Mathematics Education and RINS, Gyeongsang National University, Chinju, 660-701, Korea

${ }^{3}$ Department of Mathematics, King Abdulaziz University, P.O. Box 80203 Jeddah, Saudi Arabia

Full list of author information is available at the end of the article

\begin{abstract}
In this paper, an implicit net with perturbations for solving the mixed equilibrium problems and fixed point problems has been constructed and it is shown that the proposed net converges strongly to a common solution of the mixed equilibrium problems and fixed point problems. Also, as applications, some corollaries for solving the minimum-norm problems are also included.

MSC: 47J05; 47J25; 47H09
\end{abstract}

Keywords: equilibrium problem; fixed point problem; minimization problem; nonexpansive mapping

\section{Introduction}

The present paper is devoted to solving the following mixed equilibrium problem: Find $u \in C$ such that

$$
F(u, v)+\langle A u, v-u\rangle \geq 0
$$

for all $v \in C$, where $C$ is a nonempty closed convex subset of a real Hilbert space $H, F$ : $C \times C \rightarrow R$ is a bifunction and $A: C \rightarrow H$ is a nonlinear operator. The solution set of (1.1) is denoted by $\mathrm{S}(\mathrm{MEP})$.

This problem (1.1) includes optimization problems, variational inequalities, minimax problems, and Nash equilibrium problems in noncooperative games as special cases.

Case 1. If $A=0$ in (1.1), then (1.1) reduces to the following equilibrium problem: Find $u \in C$ such that

$$
F(u, v) \geq 0
$$

for all $v \in C$. The solution of (1.2) is denoted by $\mathrm{S}(\mathrm{EP})$.

Case 2. If $F=0$ in (1.1), then (1.1) reduces to the variational inequality problem: Find $z \in C$ such that

$$
\langle A u, v-u\rangle \geq 0
$$

for all $v \in C$. The solution of (1.2) is denoted by $\mathrm{S}(\mathrm{VI})$. 
In the literature, there are a large number of references associated with some equilibrium problems and variational inequality problems (see, for instance, [1-32]).

The main purpose of the present paper is to construct the following implicit net with perturbations for solving the mixed equilibrium (1.1) and the fixed point problem:

$$
F\left(z_{t}, y\right)+\frac{1}{\lambda}\left\langle y-z_{t}, z_{t}-\left(t u_{t}+(1-t) T z_{t}-\lambda A T z_{t}\right)\right\rangle \geq 0
$$

for all $y \in C$. Also, it is shown that the proposed net $\left\{z_{t}\right\}$ converges strongly to a common solution of the mixed equilibrium problems and fixed point problems. As applications, some corollaries for solving the minimum-norm problems are also included.

\section{Preliminaries}

Let $H$ be a real Hilbert space with an inner product $\langle\cdot, \cdot\rangle$ and a norm $\|\cdot\|$, respectively, and $C$ be a nonempty closed convex subset of a real Hilbert space $H$.

(1) A mapping $T: C \rightarrow C$ is said to be nonexpansive if

$$
\|T u-T v\| \leq\|u-v\|
$$

for all $u, v \in C . F(T)$ denotes the set of fixed points of $T$.

(2) A mapping $A: C \rightarrow H$ is said to be $\alpha$-inverse-strongly monotone if there exists a positive real number $\alpha>0$ such that

$$
\langle A u-A v, u-v\rangle \geq \alpha\|A u-A v\|^{2}
$$

for all $u, v \in C$. It is clear that any $\alpha$-inverse-strongly monotone mapping is monotone and $\frac{1}{\alpha}$-Lipschitz continuous.

Throughout this paper, we assume that a bifunction $F: C \times C \rightarrow R$ satisfies the following conditions:

(C1) $F(u, u)=0$ for all $u \in C$;

(C2) $F$ is monotone, i.e., $F(u, v)+F(v, u) \leq 0$ for all $u, v \in C$;

(C3) for each $u, v, w \in C, \lim _{t \downarrow 0} F(t w+(1-t) u, v) \leq F(u, v)$;

(C4) for each $u \in C, v \mapsto F(u, v)$ is convex and lower semicontinuous.

In fact, some efforts to construct the algorithms for solving the equilibrium problems have been carried out. For instance, Moudafi [15] presented an iterative algorithm and proved a weak convergence theorem for solving the mixed equilibrium problem (1.1). Takahashi and Takahashi [24] constructed the following iterative algorithm:

$$
\left\{\begin{array}{l}
F\left(z_{n}, y\right)+\left\langle A x_{n}, y-z_{n}\right\rangle+\frac{1}{\lambda_{n}}\left\langle y-z_{n}, z_{n}-x_{n}\right\rangle \geq 0, \\
x_{n+1}=\beta_{n} x_{n}+T\left(\alpha_{n} u+\left(1-\beta_{n}\right) z_{n}\right)
\end{array}\right.
$$

for all $y \in C$ and $n \geq 0$, where $T: C \rightarrow C$ is a nonexpansive mapping. They proved that the sequence $\left\{x_{n}\right\}$ generated by $(2.1)$ converges strongly to $z=\operatorname{Proj}_{F(T) \cap S(M E P)}(u)$.

Plubtieng and Punpaeng [20] introduced and considered the following two iterative schemes for finding a common element of the set of solutions of the problem (1.2) and the set of fixed points of a nonexpansive mapping in a Hilbert space $H$. 
Implicit iterative algorithm $\left\{x_{n}\right\}$ :

$$
\left\{\begin{array}{l}
F\left(u_{n}, y\right)+\frac{1}{r_{n}}\left\langle y-u_{n}, u_{n}-x_{n}\right\rangle \geq 0 \\
x_{n}=\alpha_{n} \gamma f\left(x_{n}\right)+\left(I-\alpha_{n} A\right) T u_{n}
\end{array}\right.
$$

for all $y \in H$ and $n \geq 1$.

Explicit iterative algorithm $\left\{x_{n}\right\}$ :

$$
\left\{\begin{array}{l}
F\left(u_{n}, y\right)+\frac{1}{r_{n}}\left\langle y-u_{n}, u_{n}-x_{n}\right\rangle \geq 0, \\
x_{n+1}=\alpha_{n} \gamma f\left(x_{n}\right)+\left(I-\alpha_{n} A\right) T u_{n}
\end{array}\right.
$$

for all $y \in H$ and $n \geq 1$.

They proved that, under certain conditions, the sequences $\left\{x_{n}\right\}$ generated by (2.2) and (2.3) converge strongly to the unique solution of the variational inequality:

$$
\langle(A-\gamma f) z, x-z\rangle \geq 0
$$

for all $x \in F(T) \cap S(E P)$, which is the optimality condition for the minimization problem:

$$
\min _{x \in F(T) \cap S(E P)} \frac{1}{2}\langle A x, x\rangle-h(x),
$$

where $h$ is a potential function for $\gamma f$.

We know that there are perturbations always occurring in the iterative processes because the manipulations are inaccurate. Recently, Chuang et al. ([8]) constructed the following iteration process with perturbations for finding a common element of the set of solutions of the equilibrium problem and the set of fixed points for a quasi-nonexpansive mapping with perturbation: $q_{1} \in H$ and

$$
\left\{\begin{array}{l}
x_{n} \in C \quad \text { such that } F\left(x_{n}, y\right)+\frac{1}{\lambda_{n}}\left\langle y-x_{n}, x_{n}-q_{n}\right\rangle \geq 0, \\
q_{n+1}=\alpha_{n} u_{n}+\left(1-\alpha_{n}\right)\left(\beta_{n} x_{n}+\left(1-\beta_{n}\right) T x_{n}\right)
\end{array}\right.
$$

for all $y \in C$ and $n \geq 0$. They shown that the sequence $\left\{q_{n}\right\}$ converges strongly to $\operatorname{Proj}_{F(T) \cap S(E P)}$.

Now, we need the following useful lemmas for our main results.

Lemma 2.1 [11] Let $C$ be a nonempty closed convex subset of a real Hilbert space $H$. Let $F: C \times C \rightarrow R$ be a bifunction which satisfies the conditions (C1)-(C4). Let $r>0$ and $x \in H$. Then there exists $z \in C$ such that

$$
F(z, y)+\frac{1}{r}\langle y-z, z-x\rangle \geq 0
$$

for all $y \in C$. Further, if

$$
T_{r}(x)=\left\{z \in C: F(z, y)+\frac{1}{r}\langle y-z, z-x\rangle \geq 0, \forall y \in C\right\},
$$

then the following hold: 
(1) $T_{r}$ is single-valued and $T_{r}$ is firmly nonexpansive, i.e., for any $x, y \in H$,

$$
\left\|T_{r} x-T_{r} y\right\|^{2} \leq\left\langle T_{r} x-T_{r} y, x-y\right\rangle
$$

(2) $S(E P)$ is closed and convex and $S(E P)=F\left(T_{r}\right)$.

Lemma 2.2 [24] Let $C, H, F$, and $T_{r} x$ be as in Lemma 2.1. Then the following holds:

$$
\left\|T_{s} x-T_{t} x\right\|^{2} \leq \frac{s-t}{s}\left\langle T_{s} x-T_{t} x, T_{s} x-x\right\rangle
$$

for all $s, t>0$ and $x \in H$.

Lemma 2.3 [24] Let $C$ be a nonempty closed convex subset of a real Hilbert space $H$. Let a mapping $A: C \rightarrow H$ be $\alpha$-inverse-strongly monotone and $r>0$ be a constant. Then we have

$$
\|(I-r A) x-(I-r A) y\|^{2} \leq\|x-y\|^{2}+r(r-2 \alpha)\|A x-A y\|^{2}
$$

for all $x, y \in C$. In particular, if $0 \leq r \leq 2 \alpha$, then $I-r A$ is nonexpansive.

Lemma 2.4 [33] Let $C$ be a closed convex subset of a real Hilbert space $H$ and let $T: C \rightarrow C$ be a nonexpansive mapping. Then the mapping $I-T$ is demiclosed, that is, if $\left\{x_{n}\right\}$ is a sequence in $C$ such that $x_{n} \rightarrow u$ weakly and $(I-T) x_{n} \rightarrow v$ strongly, then $(I-T) u=v$.

\section{Convergence results}

In this section, first, we give our main results.

Part I: Assumptions on the setting of $C, F, A$, and $T$ :

(A1) $C$ is a nonempty closed convex subset of a real Hilbert space $H$;

(A2) $F: C \times C \rightarrow R$ is a bifunction satisfying the conditions (C1)-(C4);

(A3) $A: C \rightarrow H$ is an $\alpha$-inverse-strongly monotone mapping;

(A4) $T: C \rightarrow C$ is a nonexpansive mapping.

Part II: Parameter restrict:

$\lambda$ is a constant satisfying $a \leq \lambda \leq b$, where $[a, b] \subset(0,2 \alpha)$.

Part III: Perturbations:

$\left\{u_{t}\right\} \subset H$ is a net satisfying $\lim _{t \rightarrow 0+} u_{t}=u \in H$.

Algorithm 3.1 For any $t \in\left(0,1-\frac{\lambda}{2 \alpha}\right)$, define a net $\left\{z_{t}\right\} \subset C$ by the implicit manner:

$$
F\left(z_{t}, y\right)+\frac{1}{\lambda}\left\langle y-z_{t}, z_{t}-\left(t u_{t}+(1-t) T z_{t}-\lambda A T z_{t}\right)\right\rangle \geq 0
$$

for all $y \in C$.

Remark 3.2 We show that the net $\left\{z_{t}\right\}$ is well defined. Next, we prove that (3.1) can be rewritten as

$$
z_{t}=T_{\lambda}\left(t u_{t}+(1-t) T z_{t}-\lambda A T z_{t}\right)
$$

for all $t \in\left(0,1-\frac{\lambda}{2 \alpha}\right)$. 
In fact, for any $t \in\left(0,1-\frac{\lambda}{2 \alpha}\right), u_{t} \in H$, and $x \in H$, we find $z$ such that, for all $y \in C$,

$$
F(z, y)+\frac{1}{\lambda}\left\langle y-z, z-\left(t u_{t}+(1-t) T x-\lambda A T x\right)\right\rangle \geq 0 .
$$

From Lemma 2.1, we get immediately

$$
z=T_{\lambda}\left(t u_{t}+(1-t) T x-\lambda A T x\right)
$$

Now, we can define a mapping

$$
\vartheta_{t}:=T_{\lambda}\left(t u_{t}+(1-t) T-\lambda A T\right)
$$

for all $t \in\left(0,1-\frac{\lambda}{2 \alpha}\right)$. Again, from Lemma 2.1, we know that $T_{\lambda}$ is nonexpansive. Thus, for any $x, y \in C$, we have

$$
\begin{aligned}
& \left\|\vartheta_{t} x-\vartheta_{t} y\right\| \\
& \quad=\left\|T_{\lambda}\left(t u_{t}+(1-t) T x-\lambda A T x\right)-T_{\lambda}\left(t u_{t}+(1-t) T y-\lambda A T y\right)\right\| \\
& \quad \leq\left\|\left(t u_{t}+(1-t) T x-\lambda A T x\right)-\left(t u_{t}+(1-t) T y-\lambda A T y\right)\right\| \\
& \quad=(1-t)\left\|\left(I-\frac{\lambda}{1-t} A\right) T x-\left(I-\frac{\lambda}{1-t} A\right) T y\right\| .
\end{aligned}
$$

From Lemma 2.3, $I-\frac{\lambda}{1-t} A$ is nonexpansive for all $t \in\left(0,1-\frac{\lambda}{2 \alpha}\right)$. Note that $T$ is also nonexpansive. By (3.3), we deduce

$$
\left\|\vartheta_{t} x-\vartheta_{t} y\right\| \leq(1-t)\|x-y\|
$$

for all $x, y \in C$. This indicates that $\vartheta_{t}$ is a contraction on $C$ and so it has a unique fixed point, denoted by $z_{t}$, in $C$. That is, $z_{t}=T_{\lambda}\left(t u_{t}+(1-t) T z_{t}-\lambda A T z_{t}\right)$. Hence $\left\{z_{t}\right\}$ is well defined.

Theorem 3.3 Suppose that $F(T) \cap S(M E P) \neq \emptyset$. Then the net $\left\{z_{t}\right\}$ defined by (3.1) converges strongly as $t \rightarrow 0+$ to $P_{F(T) \cap S(M E P)}(u)$.

Proof Pick up $z \in F(T) \cap S(M E P)$. It is obvious that $z=T_{\lambda}(z-\lambda A z)$ for all $\lambda>0$. So, we have

$$
z=T z=T_{\lambda}(z-\lambda A z)=T_{\lambda}(T z-\lambda A T z)=T_{\lambda}\left(t T z+(1-t)\left(T z-\frac{\lambda}{1-t} A T z\right)\right)
$$

for all $t \in\left(0,1-\frac{\lambda}{2 \alpha}\right)$. Then we have

$$
\begin{aligned}
\| z_{t} & -z \|^{2} \\
& =\left\|T_{\lambda}\left(t u_{t}+(1-t) T z_{t}-\lambda A T z_{t}\right)-z\right\|^{2} \\
& =\left\|T_{\lambda}\left(t u_{t}+(1-t)\left(T z_{t}-\frac{\lambda}{1-t} A T z_{t}\right)\right)-T_{\lambda}\left(t z+(1-t)\left(T z-\frac{\lambda}{1-t} A T z\right)\right)\right\|^{2}
\end{aligned}
$$




$$
\begin{aligned}
& \leq\left\|\left(t u_{t}+(1-t)\left(T z_{t}-\frac{\lambda}{1-t} A T z_{t}\right)\right)-\left(t z+(1-t)\left(T z-\frac{\lambda}{1-t} A T z\right)\right)\right\|^{2} \\
& =\left\|(1-t)\left(\left(T z_{t}-\frac{\lambda}{1-t} A T z_{t}\right)-\left(T z-\frac{\lambda}{1-t} A T z\right)\right)+t\left(u_{t}-z\right)\right\|^{2} .
\end{aligned}
$$

Using the convexity of $\|\cdot\|$ and the inverse-strong monotonicity of $A$, we derive

$$
\begin{aligned}
&\left\|(1-t)\left(\left(T z_{t}-\frac{\lambda}{1-t} A T z_{t}\right)-\left(T z-\frac{\lambda}{1-t} A T z\right)\right)+t\left(u_{t}-z\right)\right\|^{2} \\
& \leq(1-t)\left\|\left(T z_{t}-\frac{\lambda}{1-t} A T z_{t}\right)-\left(T z-\frac{\lambda}{1-t} A T z\right)\right\|^{2}+t\left\|u_{t}-z\right\|^{2} \\
&=(1-t)\left\|\left(T z_{t}-T z\right)-\lambda\left(A T z_{t}-A T z\right) /(1-t)\right\|^{2}+t\left\|u_{t}-z\right\|^{2} \\
&=(1-t)\left(\left\|T z_{t}-T z\right\|^{2}-\frac{2 \lambda}{1-t}\left\langle A T z_{t}-A T z, T z_{t}-T z\right\rangle\right. \\
&\left.+\frac{\lambda^{2}}{(1-t)^{2}}\left\|A T z_{t}-A T z\right\|^{2}\right)+t\left\|u_{t}-z\right\|^{2} \\
& \leq(1-t)\left(\left\|T z_{t}-T z\right\|^{2}-\frac{2 \alpha \lambda}{1-t}\left\|A T z_{t}-A T z\right\|^{2}+\frac{\lambda^{2}}{(1-t)^{2}}\left\|A T z_{t}-A T z\right\|^{2}\right) \\
&+t\left\|u_{t}-z\right\|^{2} \\
&=(1-t)\left(\left\|T z_{t}-T z\right\|^{2}+\frac{\lambda}{(1-t)^{2}}(\lambda-2(1-t) \alpha)\left\|A T z_{t}-A T z\right\|^{2}\right)+t\left\|u_{t}-z\right\|^{2} \\
& \leq(1-t)\left(\left\|z_{t}-z\right\|^{2}+\frac{\lambda}{(1-t)^{2}}(\lambda-2(1-t) \alpha)\left\|A T z_{t}-A T z\right\|^{2}\right)+t\left\|u_{t}-z\right\|^{2} .
\end{aligned}
$$

By the assumption, we have $\lambda-2(1-t) \alpha \leq 0$ for all $t \in\left(0,1-\frac{\lambda}{2 \alpha}\right)$. Then, from (3.4) and (3.5), it follows that

$$
\begin{aligned}
\| z_{t} & -z \|^{2} \\
& \leq(1-t)\left(\left\|z_{t}-z\right\|^{2}+\frac{\lambda}{(1-t)^{2}}(\lambda-2(1-t) \alpha)\left\|A T z_{t}-A T z\right\|^{2}\right)+t\left\|u_{t}-z\right\|^{2} \\
& \leq(1-t)\left\|z_{t}-z\right\|^{2}+t\left\|u_{t}-z\right\|^{2}
\end{aligned}
$$

and so

$$
\left\|z_{t}-z\right\| \leq\left\|u_{t}-z\right\|
$$

Since $\lim _{t \rightarrow 0+} u_{t}=u$, there exists a positive constant $M>0$ such that $\sup _{t}\left\{\left\|u_{t}\right\|\right\} \leq M$. Then, from (3.7), we deduce that $\left\{z_{t}\right\}$ is bounded. Hence $\left\{T z_{t}\right\}$ and $\left\{A T z_{t}\right\}$ are also bounded. From (3.4) and (3.5), we obtain

$$
\left\|z_{t}-z\right\|^{2} \leq(1-t)\left\|z_{t}-z\right\|^{2}+\frac{\lambda}{(1-t)}(\lambda-2(1-t) \alpha)\left\|A T z_{t}-A z\right\|^{2}+t\left\|u_{t}-z\right\|^{2}
$$

and so

$$
\frac{\lambda}{(1-t)}(2(1-t) \alpha-\lambda)\left\|A T z_{t}-A z\right\|^{2} \leq t\left\|u_{t}-z\right\|^{2} \rightarrow 0 .
$$


This implies that

$$
\lim _{t \rightarrow 0+}\left\|A T z_{t}-A z\right\|=0 .
$$

Next, we show $\left\|z_{t}-T z_{t}\right\| \rightarrow 0$. Since $T_{\lambda}$ is firmly nonexpansive (see Lemma 2.1), we have

$$
\begin{aligned}
\left\|z_{t}-z\right\|^{2}= & \left\|T_{\lambda}\left(t u_{t}+(1-t) T z_{t}-\lambda A T z_{t}\right)-z\right\|^{2} \\
= & \left\|T_{\lambda}\left(t u_{t}+(1-t) T z_{t}-\lambda A T z_{t}\right)-T_{\lambda}(T z-\lambda A T z)\right\|^{2} \\
\leq & \left\langle t u_{t}+(1-t) T z_{t}-\lambda A T z_{t}-(T z-\lambda A T z), z_{t}-z\right\rangle \\
= & \frac{1}{2}\left(\left\|t u_{t}+(1-t) T z_{t}-\lambda A T z_{t}-(T z-\lambda A T z)\right\|^{2}+\left\|z_{t}-z\right\|^{2}\right. \\
& \left.-\left\|t u_{t}+(1-t) T z_{t}-\lambda\left(A T z_{t}-\lambda A T z\right)-z_{t}\right\|^{2}\right) .
\end{aligned}
$$

Since $I-\lambda A /(1-t)$ is nonexpansive, we have

$$
\begin{aligned}
& \left\|t u_{t}+(1-t) T z_{t}-\lambda A T z_{t}-(T z-\lambda A T z)\right\|^{2} \\
& \quad=\left\|(1-t)\left(\left(T z_{t}-\lambda A T z_{t} /(1-t)\right)-(T z-\lambda A T z /(1-t))\right)+t\left(u_{t}-z\right)\right\|^{2} \\
& \quad \leq(1-t)\left\|\left(T z_{t}-\lambda A T z_{t} /(1-t)\right)-(T z-\lambda A T z /(1-t))\right\|^{2}+t\left\|u_{t}-z\right\|^{2} \\
& \quad \leq(1-t)\left\|T z_{t}-T z\right\|^{2}+t\left\|u_{t}-z\right\|^{2} \\
& \quad \leq(1-t)\left\|z_{t}-z\right\|^{2}+t\left\|u_{t}-z\right\|^{2} .
\end{aligned}
$$

Thus we have

$$
\begin{aligned}
\left\|z_{t}-z\right\|^{2} \leq & \frac{1}{2}\left((1-t)\left\|z_{t}-z\right\|^{2}+t\left\|u_{t}-z\right\|^{2}+\left\|z_{t}-z\right\|^{2}\right. \\
& \left.-\left\|t u_{t}+(1-t) T z_{t}-z_{t}-\lambda\left(A T z_{t}-A T z\right)\right\|^{2}\right) .
\end{aligned}
$$

It follows that

$$
\begin{aligned}
0 \leq & t\left\|u_{t}-z\right\|^{2}-\left\|t u_{t}+(1-t) T z_{t}-z_{t}-\lambda\left(A T z_{t}-A T z\right)\right\|^{2} \\
= & t\left\|u_{t}-z\right\|^{2}-\left\|t u_{t}+(1-t) T z_{t}-z_{t}\right\|^{2} \\
& \quad+2 \lambda\left\langle t u_{t}+(1-t) T z_{t}-z_{t}, A T z_{t}-A T z\right\rangle-\lambda^{2}\left\|A T z_{t}-A T z\right\|^{2} \\
\leq & t\left\|u_{t}-z\right\|^{2}-\left\|t u_{t}+(1-t) T z_{t}-z_{t}\right\|^{2} \\
& +2 \lambda\left\|t u_{t}+(1-t) T z_{t}-z_{t}\right\|\left\|A T z_{t}-A T z\right\|
\end{aligned}
$$

and so

$$
\left\|t u_{t}+(1-t) T z_{t}-z_{t}\right\|^{2} \leq t\left\|u_{t}-z\right\|^{2}+2 \lambda\left\|t u_{t}+(1-t) T z_{t}-z_{t}\right\|\left\|A T z_{t}-A z\right\| .
$$

Since $\left\|A T z_{t}-A z\right\| \rightarrow 0$ by (3.8), we deduce

$$
\lim _{t \rightarrow 0+}\left\|t u_{t}+(1-t) T z_{t}-z_{t}\right\|=0
$$


Therefore, we have

$$
\lim _{t \rightarrow 0+}\left\|z_{t}-T z_{t}\right\|=0
$$

From (3.4), it follows that

$$
\begin{aligned}
\| z_{t}- & z \|^{2} \\
\leq & \left\|(1-t)\left(\left(T z_{t}-\frac{\lambda}{1-t} A T z_{t}\right)-\left(T z-\frac{\lambda}{1-t} A T z\right)\right)+t\left(u_{t}-z\right)\right\|^{2} \\
= & (1-t)^{2}\left\|\left(T z_{t}-\frac{\lambda}{1-t} A T z_{t}\right)-\left(T z-\frac{\lambda}{1-t} A T z\right)\right\|^{2} \\
& +2 t(1-t)\left\langle u_{t}-z,\left(T z_{t}-\frac{\lambda}{1-t} A T z_{t}\right)-\left(T z-\frac{\lambda}{1-t} A T z\right)\right\rangle+t^{2}\left\|u_{t}-z\right\|^{2} \\
\leq & (1-t)^{2}\left\|z_{t}-z\right\|^{2}+2 t(1-t)\left\langle u_{t}-z, T z_{t}-\frac{\lambda}{1-t}\left(A T z_{t}-A z\right)-z\right\rangle+t^{2}\left\|u_{t}-z\right\|^{2} \\
= & (1-2 t)\left\|z_{t}-z\right\|^{2}+2 t\left\{(1-t)\left\langle u_{t}-z, T z_{t}-z-\frac{\lambda}{1-t}\left(A T z_{t}-A z\right)\right\rangle\right. \\
& \left.+t^{2}\left(\left\|u_{t}-z\right\|^{2}+\left\|z_{t}-z\right\|^{2}\right)\right\},
\end{aligned}
$$

which implies that

$$
\begin{aligned}
\left\|z_{t}-z\right\|^{2} \leq & \left\langle u_{t}-z, T z_{t}-z-\frac{\lambda}{1-t}\left(A T z_{t}-A z\right)\right\rangle+\frac{t}{2}\left(\left\|u_{t}-z\right\|^{2}+\left\|z_{t}-z\right\|^{2}\right) \\
& +t\left\|u_{t}-z\right\|\left\|T z_{t}-z-\frac{\lambda}{1-t}\left(A T z_{t}-A z\right)\right\| \\
\leq & \left\langle z-u, z-T z_{t}\right\rangle+\frac{\lambda}{1-t}\left\|u_{t}-z\right\|\left\|A T z_{t}-A z\right\|+\left(t+\left\|u_{t}-u\right\|\right) M_{1}
\end{aligned}
$$

where $M_{1}$ is a constant such that

$$
\sup \left\{\left\|u_{t}-z\right\|^{2}+\left\|z_{t}-z\right\|^{2}+\left\|u_{t}-z\right\|\left\|T z_{t}-z-\frac{\lambda}{1-t}\left(A T z_{t}-A z\right)\right\|: t \in\left(0,1-\frac{\lambda}{2 \alpha}\right)\right\} \leq M_{1}
$$

Next, we show that $\left\{z_{t}\right\}$ is relatively norm-compact as $t \rightarrow 0+$. Assume that $\left\{t_{n}\right\} \subset(0,1)$ is a sequence such that $t_{n} \rightarrow 0+$ as $n \rightarrow \infty$. Put $z_{n}:=z_{t_{n}}$. From (3.10), it follows that

$$
\begin{aligned}
& \left\|z_{n}-z\right\|^{2} \\
& \quad \leq\left\langle z-u, z-T z_{n}\right\rangle+\frac{\lambda}{1-t_{n}}\left\|u_{n}-z\right\|\left\|A T z_{n}-A z\right\|+\left(t_{n}+\left\|u_{n}-u\right\|\right) M_{1}
\end{aligned}
$$

for all $z \in F(T) \cap S(M E P)$. Since $\left\{z_{n}\right\}$ is bounded, without loss of generality, we may assume that $z_{n} \rightarrow \tilde{x} \in C$. From (3.9), we have

$$
\lim _{n \rightarrow \infty}\left\|z_{n}-T z_{n}\right\|=0
$$


We can use Lemma 2.4 to (3.12) to deduce $\tilde{x} \in F(T)$. Further, we show that $\tilde{x}$ is also in $S(M E P)$. Since $z_{n}=T_{\lambda}\left(t_{n} u_{n}+\left(1-t_{n}\right) T z_{n}-\lambda A T z_{n}\right)$ for any $y \in C$, we have

$$
F\left(z_{n}, y\right)+\left\langle A T z_{n}, y-z_{n}\right\rangle+\frac{1}{\lambda}\left\langle y-z_{n}, z_{n}-\left(t_{n} u_{n}+\left(1-t_{n}\right) T z_{n}\right)\right\rangle \geq 0 .
$$

From (C2), it follows that

$$
\left\langle A T z_{n}, y-z_{n}\right\rangle+\frac{1}{\lambda}\left\langle y-z_{n}, z_{n}-\left(t_{n} u_{n}+\left(1-t_{n}\right) T z_{n}\right)\right\rangle \geq F\left(y, z_{n}\right)
$$

Put $x_{t}=t y+(1-t) \tilde{x}$ for all $t \in\left(0,1-\frac{\lambda}{2 \alpha}\right)$ and $y \in C$. Then we have $x_{t} \in C$ and so, from (3.13), it follows that

$$
\begin{aligned}
\left\langle x_{t}-z_{n}, A x_{t}\right\rangle \geq & \left\langle x_{t}-z_{n}, A x_{t}\right\rangle-\left\langle x_{t}-z_{n}, A T z_{n}\right\rangle \\
& -\frac{1}{\lambda}\left\langle x_{t}-z_{n}, z_{n}-\left(t_{n} u_{n}+\left(1-t_{n}\right) T z_{n}\right)\right\rangle+F\left(x_{t}, z_{n}\right) \\
= & \left\langle x_{t}-z_{n}, A x_{t}-A z_{n}\right\rangle+\left\langle x_{t}-z_{n}, A z_{n}-A T z_{n}\right\rangle \\
& -\frac{1}{\lambda}\left\langle x_{t}-z_{n}, z_{n}-\left(t_{n} u_{n}+\left(1-t_{n}\right) T z_{n}\right)\right\rangle+F\left(x_{t}, z_{n}\right) .
\end{aligned}
$$

Since $\left\|z_{n}-T z_{n}\right\| \rightarrow 0$, we have $\left\|A z_{n}-A T z_{n}\right\| \rightarrow 0$. Further, since $A$ is monotone, we have $\left\langle x_{t}-z_{n}, A x_{t}-A z_{n}\right\rangle \geq 0$. So, from (C4), it follows that, as $n \rightarrow \infty$,

$$
\left\langle x_{t}-\tilde{x}, A x_{t}\right\rangle \geq F\left(x_{t}, \tilde{x}\right)
$$

Also, it follows from (C1), (C4), and (3.14) that

$$
\begin{aligned}
0 & =F\left(x_{t}, x_{t}\right) \\
& \leq t F\left(x_{t}, y\right)+(1-t) F\left(x_{t}, \tilde{x}\right) \\
& \leq t F\left(x_{t}, y\right)+(1-t)\left\langle x_{t}-\tilde{x}, A x_{t}\right\rangle \\
& =t F\left(x_{t}, y\right)+(1-t) t\left\langle y-\tilde{x}, A x_{t}\right\rangle
\end{aligned}
$$

and hence

$$
0 \leq F\left(x_{t}, y\right)+(1-t)\left\langle y-\tilde{x}, A x_{t}\right\rangle .
$$

Letting $t \rightarrow 0$, we have

$$
0 \leq F(\tilde{x}, y)+\langle y-\tilde{x}, A \tilde{x}\rangle
$$

for all $y \in C$. This implies $\tilde{x} \in E P$. Therefore, we can substitute $\tilde{x}$ for $z$ in (3.8) to get

$$
\begin{aligned}
\left\|z_{n}-\tilde{x}\right\|^{2} \leq & \left\langle\tilde{x}-u, \tilde{x}-T z_{n}\right\rangle+\frac{\lambda}{1-t_{n}}\left\|u_{n}-\tilde{x}\right\|\left\|A T z_{n}-A \tilde{x}\right\| \\
& +\left(t_{n}+\left\|u_{n}-\tilde{x}\right\|\right) M_{1}
\end{aligned}
$$


for all $\tilde{x} \in F(T) \cap S(M E P)$. By (3.5), we know that $\left\|A T z_{n}-A z\right\| \rightarrow 0$ for any $z \in F(T) \cap$ $S(M E P)$. Then we get $\left\|A T z_{n}-A \tilde{x}\right\| \rightarrow 0$. Consequently, the weak convergence of $\left\{z_{n}\right\}$ (and $\left.\left\{T z_{n}\right\}\right)$ to $\tilde{x}$ actually implies that $z_{n} \rightarrow \tilde{x}$. This proves the relative norm-compactness of the net $\left\{z_{t}\right\}$ as $t \rightarrow 0+$.

Now, we return to (3.11) and take the limit as $n \rightarrow \infty$ to get

$$
\|\tilde{x}-z\|^{2} \leq\langle z-u, z-\tilde{x}\rangle
$$

for all $z \in F(T) \cap S(M E P)$. Equivalently, we have

$$
\langle u-\tilde{x}, z-\tilde{x}\rangle \leq 0
$$

for all $z \in F(T) \cap S(M E P)$. This clearly implies that

$$
\tilde{x}=P_{F(T) \cap S(M E P)}(u) .
$$

Therefore, $\tilde{x}$ is the unique cluster point of the net $\left\{z_{t}\right\}$. Hence the whole net $\left\{z_{t}\right\}$ converges strongly to $\tilde{x}=P_{F(T) \cap S(M E P)}(u)$. This completes the proof.

\section{Induced algorithms and corollaries}

(I) Taking $T=I$ in (3.1), we get the following.

Algorithm 4.1 For any $t \in\left(0,1-\frac{\lambda}{2 \alpha}\right)$, define a net $\left\{z_{t}\right\} \subset C$ by the implicit manner:

$$
F\left(z_{t}, y\right)+\frac{1}{\lambda}\left\langle y-z_{t}, z_{t}-\left(t u_{t}+(1-t) z_{t}-\lambda A z_{t}\right)\right\rangle \geq 0
$$

for all $y \in C$.

Corollary 4.2 Suppose that $S(M E P) \neq \emptyset$. Then the net $\left\{z_{t}\right\}$ defined by (4.1) converges strongly as $t \rightarrow 0+$ to $P_{S(M E P)}(u)$.

(II) Taking $F=0$ in (4.1), we get the following.

Algorithm 4.3 For any $t \in\left(0,1-\frac{\lambda}{2 \alpha}\right)$, define a net $\left\{z_{t}\right\} \subset C$ by the implicit manner:

$$
\left\langle y-z_{t}, z_{t}-\left(t u_{t}+(1-t) z_{t}-\lambda A z_{t}\right)\right\rangle \geq 0
$$

for all $y \in C$.

Corollary 4.4 Suppose that $S(V I) \neq \emptyset$. Then the net $\left\{z_{t}\right\}$ defined by (4.2) converges strongly as $t \rightarrow 0+$ to $P_{S(V I)}(u)$.

(III) Taking $A=0$ in (4.1), we get the following.

Algorithm 4.5 For any $t \in(0,1)$, define a net $\left\{z_{t}\right\} \subset C$ by the implicit manner:

$$
F\left(z_{t}, y\right)+\frac{t}{\lambda}\left\langle y-z_{t}, z_{t}-u_{t}\right\rangle \geq 0
$$

for all $y \in C$. 
Corollary 4.6 Suppose that $S(E P) \neq \emptyset$. Then the net $\left\{z_{t}\right\}$ defined by (4.3) converges strongly as $t \rightarrow 0+$ to $P_{S(E P)}(u)$.

\section{Minimum-norm solutions}

In many problems, one needs to find a solution with the minimum norm. In an abstract way, we may formulate such problems as finding a point $x^{\dagger}$ with the property:

$$
x^{\dagger} \in C, \quad\left\|x^{\dagger}\right\|^{2}=\min _{x \in C}\|x\|^{2},
$$

where $C$ is a nonempty closed convex subset of a real Hilbert space $H$. In other words, $x^{\dagger}$ is the (nearest point or metric) projection of the origin onto $C$, that is,

$$
x^{\dagger}=P_{C}(0)
$$

where $P_{C}$ is the metric (or nearest point) projection from $H$ onto $C$.

A typical example is the least-squares solution of the constrained linear inverse problem:

$$
\left\{\begin{array}{l}
A x=b, \\
x \in C,
\end{array}\right.
$$

where $A$ is a bounded linear operator from $H$ to another real Hilbert space $H_{1}$ and $b$ is a given point in $H_{1}$. The least-squares solution is the least-norm minimizer of the minimization problem:

$$
\min _{x \in C}\|A x-b\|^{2}
$$

Motivated by the above least-squares solution of the constrained linear inverse problems, we study the general case of finding the minimum-norm solutions for the mixed equilibrium problem (1.1), the equilibrium problem (1.2), the variational inequality (1.3), and the fixed point problem.

Now, we state our algorithms which can be inducted from the above section.

(I) Taking $u_{t}=0$ for all $t$ in (3.1), we get the following.

Algorithm 5.1 For any $t \in\left(0,1-\frac{\lambda}{2 \alpha}\right)$, define a net $\left\{z_{t}\right\} \subset C$ by the implicit manner:

$$
F\left(z_{t}, y\right)+\frac{1}{\lambda}\left\langle y-z_{t}, z_{t}-\left((1-t) T z_{t}-\lambda A T z_{t}\right)\right\rangle \geq 0
$$

for all $y \in C$.

Corollary 5.2 Suppose that $F(T) \cap S(M E P) \neq \emptyset$. Then the net $\left\{z_{t}\right\}$ defined by (5.1) converges strongly as $t \rightarrow 0+$ to $P_{F(T) \cap S(M E P)}(0)$, which is the minimum-norm element in $F(T) \cap S(M E P)$.

(II) Taking $u_{t}=0$ for all $t$ in (4.1), we get the following. 
Algorithm 5.3 For any $t \in\left(0,1-\frac{\lambda}{2 \alpha}\right)$, define a net $\left\{z_{t}\right\} \subset C$ by the implicit manner:

$$
F\left(z_{t}, y\right)+\frac{1}{\lambda}\left\langle y-z_{t}, z_{t}-\left((1-t) z_{t}-\lambda A z_{t}\right)\right\rangle \geq 0
$$

for all $y \in C$.

Corollary 5.4 Suppose that $S(M E P) \neq \emptyset$. Then the net $\left\{z_{t}\right\}$ defined by (5.2) converges strongly as $t \rightarrow 0+$ to $P_{S(M E P)}(0)$, which is the minimum-norm element in $S(M E P)$.

(III) Taking $u_{t}=0$ for all $t$ in (4.2), we get the following.

Algorithm 5.5 For any $t \in\left(0,1-\frac{\lambda}{2 \alpha}\right)$, define a net $\left\{z_{t}\right\} \subset C$ by the implicit manner:

$$
\left\langle y-z_{t}, z_{t}-\left((1-t) z_{t}-\lambda A z_{t}\right)\right\rangle \geq 0
$$

for all $y \in C$.

Corollary 5.6 Suppose that $S(V I) \neq \emptyset$. Then the net $\left\{z_{t}\right\}$ defined by (5.3) converges strongly as $t \rightarrow 0+$ to $P_{S(V I)}(0)$, which is the minimum-norm element in $S(V I)$.

(IV) Taking $A=0$ in (5.1), we get the following.

Algorithm 5.7 For any $t \in(0,1)$, define a net $\left\{z_{t}\right\} \subset C$ by the implicit manner:

$$
F\left(z_{t}, y\right)+\frac{1}{\lambda}\left\langle y-z_{t}, z_{t}-(1-t) T z_{t}\right\rangle \geq 0
$$

for all $y \in C$.

Corollary 5.8 Suppose that $F(T) \cap S(E P) \neq \emptyset$. Then the net $\left\{z_{t}\right\}$ defined by (5.4) converges strongly as $t \rightarrow 0+$ to $P_{F(T) \cap S(E P)}(0)$, which is the minimum-norm element in $F(T) \cap S(E P)$.

(V) Taking $A=0$ in (5.2), we get the following.

Algorithm 5.9 For any $t \in(0,1)$, define a net $\left\{z_{t}\right\} \subset C$ by the implicit manner:

$$
F\left(z_{t}, y\right)+\frac{t}{\lambda}\left\langle y-z_{t}, z_{t}\right\rangle \geq 0
$$

for all $y \in C$.

Corollary 5.10 Suppose that $S(E P) \neq \emptyset$. Then the net $\left\{z_{t}\right\}$ defined by (5.5) converges strongly as $t \rightarrow 0+$ to $P_{S(E P)}(0)$, which is the minimum-norm element in $S(E P)$. 


\section{Author details}

'Department of Mathematics, Tianjin Polytechnic University, Tianjin, 300387, China. ${ }^{2}$ Department of Mathematics Education and RINS, Gyeongsang National University, Chinju, 660-701, Korea. ${ }^{3}$ Department of Mathematics, King Abdulaziz University, P.O. Box 80203, Jeddah, Saudi Arabia. ${ }^{4}$ Department of Information Management, Cheng Shiu University, Kaohsiung, 833, Taiwan. ${ }^{5}$ Department of Mathematics, Texas A\&M University, Kingsville, USA.

\section{Acknowledgements}

The first author was supported in part by NSFC 11071279 and NSFC 71161001-G0105, the second author was supported by the Basic Science Research Program through the National Research Foundation of Korea (NRF) funded by the Ministry of Education, Science and Technology (Grant Number: NRF-2013053358) and the third author was supported in part by NSC 101-2628-E-230-001-MY3 and NSC 101-2622-E-230-005-CC3.

\section{Received: 25 February 2014 Accepted: 15 August 2014 Published: 2 September 2014}

\section{References}

1. Blum, E, Oettli, W: From optimization and variational inequalities to equilibrium problems. Math. Stud. $63,123-145$ (1994)

2. Ceng, LC, Schaible, S, Yao, JC: Implicit iteration scheme with perturbed mapping for equilibrium problems and fixed point problems of finitely many nonexpansive mappings. J. Optim. Theory Appl. 139, 403-418 (2008)

3. Ceng, LC, Al-Homidan, S, Ansari, QH, Yao, JC: An iterative scheme for equilibrium problems and fixed point problems of strict pseudo-contraction mappings. J. Comput. Appl. Math. 223, 967-974 (2009)

4. Chadli, O, Schaible, S, Yao, JC: Regularized equilibrium problems with an application to noncoercive hemivariational inequalities. J. Optim. Theory Appl. 121, 571-596 (2004)

5. Chadli, O, Wong, NC, Yao, JC: Equilibrium problems with applications to eigenvalue problems. J. Optim. Theory Appl. 117, 245-266 (2003)

6. Cho, YJ, Argyros, IK, Petrot, N: Approximation methods for common solutions of generalized equilibrium, systems of nonlinear variational inequalities and fixed point problems. Comput. Math. Appl. 60, 2292-2301 (2010)

7. Cho, YJ, Qin, X, Kang, Jl: Convergence theorems based on hybrid methods for generalized equilibrium problems and fixed point problems. Nonlinear Anal. 71, 4203-4214 (2009)

8. Chuang, CS, Lin, LJ, Takahashi, W: Halpern's type iterations with perturbations in Hilbert spaces: equilibrium solutions and fixed points. J. Glob. Optim. (2013). doi:10.1007/s10898-012-9911-6

9. Colao, V, Acedo, GL, Marino, G: An implicit method for finding common solutions of variational inequalities and systems of equilibrium problems and fixed points of infinite family of nonexpansive mappings. Nonlinear Anal. 71, 2708-2715 (2009)

10. Colao, V, Marino, G, Xu, HK: An iterative method for finding common solutions of equilibrium and fixed point problems. J. Math. Anal. Appl. 344, 340-352 (2008)

11. Combettes, PL, Hirstoaga, A: Equilibrium programming in Hilbert spaces. J. Nonlinear Convex Anal. 6, 117-136 (2005)

12. Jaiboon, C, Kumam, P: A general iterative method for addressing mixed equilibrium problems and optimization problems. Nonlinear Anal. 73, 1180-1202 (2010)

13. Konnov, IV, Schaible, S, Yao, JC: Combined relaxation method for mixed equilibrium problems. J. Optim. Theory Appl. $126,309-322(2005)$

14. Moudafi, A, Théra, M: Proximal and dynamical approaches to equilibrium problems. In: III-Posed Variational Problems and Regularization Techniques. Lecture Notes in Economics and Mathematical Systems, vol. 477, pp. 187-201. Springer, Berlin (1999)

15. Moudafi, A: Weak convergence theorems for nonexpansive mappings and equilibrium problems. J. Nonlinear Convex Anal. 9, 37-43 (2008)

16. Noor, MA: Multivalued general equilibrium problems. J. Math. Anal. Appl. 283, 140-149 (2003)

17. Noor, MA, Rassias, TM: On nonconvex equilibrium problems. J. Math. Anal. Appl. 312, 289-299 (2005)

18. Peng, JW, Yao, JC: A new hybrid-extragradient method for generalized mixed equilibrium problems, fixed point problems and variational inequality problems. Taiwan. J. Math. 12, 1401-1432 (2008)

19. Petrot, N, Wattanawitoon, K, Kumam, P: A hybrid projection method for generalized mixed equilibrium problems and fixed point problems in Banach spaces. Nonlinear Anal. Hybrid Syst. 4, 631-643 (2010)

20. Plubtieng, S, Punpaeng, R: A general iterative method for equilibrium problems and fixed point problems in Hilbert spaces. J. Math. Anal. Appl. 336, 455-469 (2007)

21. Qin, X, Cho, YJ, Kang, SM: Viscosity approximation methods for generalized equilibrium problems and fixed point problems with applications. Nonlinear Anal. 72, 99-112 (2010)

22. Shehu, Y: Strong convergence theorems for nonlinear mappings, variational inequality problems and system of generalized mixed equilibrium problems. Math. Comput. Model. 54, 2259-2276 (2011)

23. Takahashi, S, Takahashi, W: Viscosity approximation methods for equilibrium problems and fixed point problems in Hilbert spaces. J. Math. Anal. Appl. 331, 506-515 (2007)

24. Takahashi, S, Takahashi, W: Strong convergence theorem for a generalized equilibrium problem and a nonexpansive mapping in a Hilbert space. Nonlinear Anal. 69, 1025-1033 (2008)

25. Tada, A, Takahashi, W: Strong convergence theorem for an equilibrium problem and a nonexpansive mapping. In: Takahashi, W, Tanaka, T (eds.) Nonlinear Analysis and Convex Analysis, pp. 607-617. Yokohama Publishers, Yokohama (2007)

26. Yao, Y, Cho, YJ, Liou, YC: Algorithms of common solutions for variational inclusions, mixed equilibrium problems and fixed point problems. Eur. J. Oper. Res. 212, 242-250 (2011)

27. Yao, Y, Liou, YC, Yao, JC: Convergence theorem for equilibrium problems and fixed point problems of infinite family of nonexpansive mappings. Fixed Point Theory Appl. 2007, Article ID 64363 (2007)

28. Yao, Y, Liou, YC: Composite algorithms for minimization over the solutions of equilibrium problems and fixed point problems. Abstr. Appl. Anal. 2010, Article ID 763506 (2010)

29. Yao, Y, Shahzad, N: New methods with perturbations for non-expansive mappings in Hilbert spaces. Fixed Point Theory Appl. 2011, 79 (2011) 
30. Zegeye, H, Ofoedu, EU, Shahzad, N: Convergence theorems for equilibrium problem, variational inequality problem and countably infinite relatively quasi-nonexpansive mappings. Appl. Math. Comput. 216, 3439-3449 (2010)

31. Zegeye, $H$, Shahzad, N: A hybrid scheme for finite families of equilibrium, variational inequality and fixed point problems. Nonlinear Anal. 74, 263-272 (2011)

32. Zhang, SS, Lee, JHW, Chan, CK: Algorithms of common solutions for quasi variational inclusion and fixed point problems. Appl. Math. Mech. 29, 571-581 (2008)

33. Zhou, $\mathrm{H}$ : Convergence theorems of fixed points for $\lambda$-strict pseudo-contractions in Hilbert spaces. Nonlinear Anal. $69,456-462(2008)$

doi:10.1186/1029-242X-2014-334

Cite this article as: Yao et al.: Constructed nets with perturbations for equilibrium and fixed point problems. Journal of Inequalities and Applications 2014 2014:334.

Submit your manuscript to a SpringerOpen ${ }^{\circ}$ journal and benefit from:

- Convenient online submission

- Rigorous peer review

- Immediate publication on acceptance

- Open access: articles freely available online

- High visibility within the field

- Retaining the copyright to your article

Submit your next manuscript at $>$ springeropen.com 